University of Wollongong

Research Online

Faculty of Engineering and Information

Faculty of Engineering and Information

Sciences - Papers: Part A

Sciences

$1-1-2016$

Predicting dropout in dietary weight loss trials using demographic and early weight change characteristics: implications for trial design

Marijka Batterham

University of Wollongong, marijka@uow.edu.au

Linda C. Tapsell

University of Wollongong, Itapsell@uow.edu.au

Karen E. Charlton

University of Wollongong, karenc@uow.edu.au

Follow this and additional works at: https://ro.uow.edu.au/eispapers

Part of the Engineering Commons, and the Science and Technology Studies Commons

Research Online is the open access institutional repository for the University of Wollongong. For further information contact the UOW Library: research-pubs@uow.edu.au 


\title{
Predicting dropout in dietary weight loss trials using demographic and early weight change characteristics: implications for trial design
}

\author{
Abstract \\ Summary Attrition causes analytical and efficacy issues in weight loss trials. Consistent predictors of \\ attrition in weight loss trials have not been identified. Trial design could be improved if factors predicting \\ attrition are accounted for. The aim of this study is to quantify the effect of easily measured pre study and \\ early study variables to determine their relationship with attrition in dietary weight loss trials. Methods \\ Data was pooled from four previous dietary weight loss trials. Mixed effects logistic regression, Receiver \\ Operator Curves and decision trees (classification and regression trees) were used to determine which of \\ the variables (percent weight loss at 1 month, age, gender and baseline BMI) predicted dropout and to \\ determine cutoffs useful for future trial design. Results The sample included 289 subjects, $73 \%$ female, \\ with a mean age of $46.68 \pm 9.27$ years and average dropout of $25 \%$. Percent weight loss at 1 month was \\ the strongest predictor of dropout, those with a weight loss $\leq 2 \%$ were 4.99 times $(95 \% \mathrm{Cl} 2.71,9.18)$ \\ more likely to drop out than those with a weight loss $>2 \%$ in the first month $(P<0.001)$. When considering \\ only data available at the beginning of a trial those $\leq 50$ years old were 2.07 times $(95 \% \mathrm{Cl} 1.2,3.5)$ more \\ likely to drop out than those $>50(P=0.006)$. Discussion Early weight loss and age were identified as \\ significant variables for predicting attrition in weight loss trials. Trial designs maybe improved by \\ incorporating these variables and developing interventions targeting these factors may improve \\ participant retention.

\section{Disciplines} \\ Engineering | Science and Technology Studies

\section{Publication Details} \\ Batterham, M., Tapsell, L. C. \& Charlton, K. E. (2016). Predicting dropout in dietary weight loss trials using \\ demographic and early weight change characteristics: implications for trial design. Obesity Research and \\ Clinical Practice, 10 (2), pp. 189-196.
}


Obes Res Clin Pract. 2015 Jun 1. pii: S1871-403X(15)00069-1. doi: 10.1016/j.orcp.2015.05.005. [Epub ahead of print]PMID: 26044614

Predicting dropout in dietary weight loss trials using demographic and early weight change characteristics: Implications for trial design.

Marijka Batterham MSc(Nutr\&Diet) MMedStat PhD AdvAPD AStat, Associate Professor, Director, Statistical Consulting Centre National Institute for Applied Statistics Research Australia School of Mathematics and Applied Statistics, University of Wollongong NSW Australia

Linda C Tapsell BSc Dip Nutr Diet MHPEd PhD FDAA, Professor, Discipline Leader, Nutrition and Dietetics School of Medicine / Faculty of Science, Medicine and Health University of Wollongong, NSW Australia

Karen E Charlton MPhil(Epi), MSc, PhD, APD, RPHNutr.

Associate Professor

School of Medicine/ Faculty of Science, Medicine and Health

University of Wollongong NSW Australia

Address Correspondance to:

Associate Professor Marijka Batterham

Director, Statistical Consulting Centre

National Institute for Applied Statistics Research Australia

School of Mathematics and Applied Statistics, University of Wollongong

Northfields Ave, Wollongong NSW 2522 Australia

Ph 61242218190 email: marijka@uow.edu.au 
Funding for the studies was provided by the Australian National Health and Medical Research Council (Project grant number 514631 and 354111) and by Horticulture Australia Limited using the vegetable levy and matched funding from the Australian Government. The authors have no conflicts of interest to declare.

Keywords: obesity, attrition, dietary intervention 
Abstract

Attrition causes analytical and efficacy issues in weight loss trials. Consistent predictors of attrition in weight loss trials have not been identified. Trial design could be improved if factors predicting attrition are accounted for. The aim of this study is to quantify the effect of easily measured pre study and early study variables to determine their relationship with attrition in dietary weight loss trials.

Methods

Data was pooled from four previous dietary weight loss trials. Mixed effects logistic regression, Receiver Operator Curves and decision trees (classification and regression trees) were used to determine which of the variables (percent weight loss at 1 month, age, gender and baseline BMI) predicted dropout and to determine cutoffs useful for future trial design.

Results

The sample included 289 subjects, $73 \%$ female, with a mean age of $46.68 \pm 9.27$ years and average dropout of $25 \%$. Percent weight loss at 1 month was the strongest predictor of dropout, those with a weight loss $\leq 2 \%$ were 4.99 times $(95 \% \mathrm{Cl} 2.71,9.18)$ more likely to drop out than those with a weight loss $>2 \%$ in the first month $(\mathrm{P}<0.001)$. When considering only data available at the beginning of a trial those $\leq$ to 50 years old were 2.07 times $(95 \% \mathrm{Cl}$ 1.2,3.5) more likely to drop out than those $>50(P=0.006)$.

Discussion

Early weight loss and age were identified as significant variables for predicting attrition in weight loss trials. Trial designs maybe improved by incorporating these variables and developing interventions targeting these factors may improve participant retention. 
Introduction

Study attrition or drop out raises major analytical and efficacy issues in weight management trials ${ }^{1}$. Determining predictors of attrition is crucial for appropriately designing weight loss interventions and the subsequent design features to test their effect. A systematic review considered demographic and psychological factors and their relationship with attrition ${ }^{2}$, consistent factors were not identified.

The aim of this research is to consider simple demographic variables collected prior to study commencement and initial weight loss and their role in predicting dropout in dietary based weight loss studies. Quantifying these variables would assist with study design in establishing criteria for stratification and randomisation.

Methods

This study was a pooled analysis of 4 previously published studies ${ }^{3-6}$. All studies were registered (www.anzctr.org.au ACTRN12608000425392, ACTRN12610000784011, ACTRN12608000453381, ACTRN12606000530527). Studies one and two were one year studies, the first involved a treatment arm focussing on increasing vegetable intake compared with standard dietary advice based on the Australian Guide to Healthy Eating ${ }^{3}$. The second study again had a control arm based on the Australian Guide to Healthy Eating. The treatment arms in this study involved increasing fish intake alone or in combination with a supplement to increase the amount of long chain n3 polyunsaturated fatty acids ${ }^{4}$. Studies three and four were 12 weeks studies, study 3 compared diets high in protein from meat or soy sources to a low fat control and study 4 had 4 arms comparing an isocaloric low fat, isocaloric with $10 \%$ polyunsaturated fatty acids, low calorie low fat and low calorie with $10 \%$ PUFA. All trials had similar inclusion criteria which included BMI $25-35 \mathrm{~kg} / \mathrm{m}^{2}$ and age $18-65$ years ${ }^{3}$ for study one, or BMI $25-37 \mathrm{~kg} / \mathrm{m}^{2}$, age $18-60$ years for study 2 and $3^{4,5}$, and 
$\mathrm{BMI}>25 \mathrm{~kg} / \mathrm{m}^{2}$ and age $>18$ years for study $4^{6}$. Exclusion criteria for all studies included major illnesses (such as cancer), chronic diseases such as diabetes or voluntary weight loss proceeding the study period. Those participants who unwilling to comply with the specific dietary interventions were also excluded prior to randomisation. In addition those with $\mathrm{LDL} \geq 6 \mathrm{mmol} / \mathrm{l}$ and those taking fish oil supplements in the last 12 weeks were excluded from study $2^{4}$. Institutional ethics approval was granted for all initial studies and for this pooled analysis. Data extracted from the studies included the weight at 1, 3 and then 12 months for studies 1 and 2, baseline BMI, age, gender, and dropout (attrition) was also recorded.

Data analysis

Baseline characteristics for the four study samples were summarised using descriptive statistics and compared using one way ANOVA for continuous variables with post hoc comparisons using Bonferroni adjustment. The Pearson Chi Square statistic was used to compare proportions, post hoc comparisons were conducted using Bonferroni adjusted z tests for comparing columns.

Characteristics predicting attrition were modelled, adjusting for clustering within study, using generalised linear models. Initially percent weight loss, age and BMI were compared as continuous variables. XTMELOGIT in STATA (V 12 Cary, NC) was used to perform the cluster mixed effects logistic regression, where study was considered a random effect. Models were compared using the likelihood ratio test. While logistic regression presents an odds of dropout which is useful in describing the importance of independent variables in predicting the outcome, in the clinical context a decision tree approach is a more useful visual method for presenting results. Various decision based analyses exist in the literature (Chapter $9^{7}$ ) including discriminant analysis and signal detection analysis. Discriminant analysis is largely surpassed by logistic regression due to less restrictive modelling assumptions and software options are limited for signal detection analysis. Decision trees 
are available in most commercial software packages are easy to interpret, in this analysis the Classification and Regression Tree procedure $\left({ }^{8}\right.$, Chapter $\left.9 \mathrm{in}^{7}\right)$ was used (SPSS V21, IBM Inc, Armonk NY ). This procedure was used to determine the predictors of dropout and to develop cutpoints. These cutpoints were then verified using undjusted Receiver Operating Curves, sensitivity and specificity by modeling different cutoffs of weight loss at one month and age for predicting attrition. Increments of $0.5 \%$ for weight loss and one year and the sample quartiles for age were considered. ROCREG in STATA was used adjusting for ties. The criteria were compared using the wald statistic. The criteria used to assess the best cutoff were the AUC, clinical relevance and the wald statistic for comparing models. These cutoff criteria were then used in additional mixed effect logistic regression models to provide odds ratios adjusted for clustering due to study.

Results

One month weights were routinely recorded for studies 1-3. For study 4 weight was only recorded at month 1 for a subset of participants. The final analysis contained 289 subjects who had a weight recorded at 1 month. Demographic details of the subjects included from the studies are shown in Table 1. Dropout varied between the parent studies and the subsets reported here (Table 1). 
Table 1. Summary statistics of the samples from the four studies

\begin{tabular}{|c|c|c|c|c|c|c|}
\hline Variable & Study $1^{3}$ & Study $2^{4}$ & Study $3^{5}$ & Study $4^{6}$ & overall & $P$ \\
\hline $\mathrm{M} / \mathrm{F}$ & $28 / 84$ & $27 / 80$ & $14 / 27$ & $10 / 19$ & & 0.525 \\
\hline $\begin{array}{l}\text { Weight } \\
\text { baseline }\end{array}$ & $84.78 \pm 11.60^{a}$ & $88.72 \pm 11.60^{a b}$ & $91.52 \pm 14.30^{b}$ & $89.00 \pm 13.30^{a b}$ & $87.62 \pm 12.37$ & 0.010 \\
\hline BMI baseline & $29.98 \pm 2.74^{a}$ & $31.18 \pm 3.41^{b}$ & $32.24 \pm 3.28^{b}$ & $31.75 \pm 3.70^{b}$ & $30.92 \pm 3.27$ & $<0.001$ \\
\hline Age & $49.00 \pm 9.41^{a}$ & $44.96 \pm 8.53^{b}$ & $46.20 \pm 8.66^{\text {ab }}$ & $44.76 \pm 10.79^{\text {ab }}$ & $46.68 \pm 9.27$ & 0.007 \\
\hline $\begin{array}{l}\text { \% weight } \\
\text { loss } 1 \text { month }\end{array}$ & $-2.60 \pm 2.16$ & $-2.66 \pm 1.88$ & $-2.71 \pm 1.93$ & $-2.74 \pm 2.37$ & $-2.65 \pm 2.04$ & 0.984 \\
\hline $\begin{array}{l}\% \text { weight } \\
\text { loss } \\
3 \text { months }\end{array}$ & $-5.29 \pm 3.45$ & $-5.31 \pm 3.48$ & $-6.02 \pm 3.86$ & $-5.21 \pm 3.56$ & $-5.39 \pm 3.52$ & 0.969 \\
\hline $\begin{array}{l}\text { \% weight } \\
\text { loss } 12 \\
\text { months }\end{array}$ & $-7.46 \pm 5.68$ & $-7.18 \pm 5.15$ & NA & NA & $-7.35 \pm 5.46$ & 0.753 \\
\hline Dropout & $19 / 112(17 \%)^{a}$ & $44 / 107(41 \%)^{b}$ & $6 / 41(15 \%)^{a}$ & $2 / 27(7 \%)^{a}$ & $71 / 289(25 \%)$ & $<0.001$ \\
\hline
\end{tabular}

${ }^{a b}$ Groups with different subscripts are significantly different $(\mathrm{P}<0.05)$ using Bonferroni adjusted $z$ tests for comparing columns.

Treatment was initially considered in the models, there was no significant effect $(P=0.654$ in model with initial weight loss and $\mathrm{P}=0.555$ in model without initial weight loss) and so this variable was not considered further. Three of the four studies demonstrated no difference in the amount of weight loss at the end of the study between treatment and control groups.

Table 2 shows the results of the mixed effects logistic regression. Models 1 shows the entry model for percent weight loss at 1 month as a continuous variable with age, BMI and gender. Using the likelihood ratio test removing any of the variables (age, BMI, gender) in a backward stepwise method did not improve the model fit $(P=0.095-0.345)$ and therefore the 
full model was retained. Removing percent weight loss from the model allowed use of criteria to determine predictors of attrition at study entry. The logistic regression model including age, BMI and gender showed that only age was significant (model 2) removing BMI or gender did not improve the model $\left(X^{2}=1.47 \mathrm{df}(1) P=0.225 \mathrm{BMl}\right.$ and $\mathrm{X}^{2}=2.83 \mathrm{df}(1) \mathrm{P}=0.093$, removing $\mathrm{BMI}$ and gender $\left.\mathrm{X}^{2}=2.83 \mathrm{df}(2) \mathrm{P}=0.145\right)$ using the likelihood ratio test.

Table 2. Multivariate mixed effects logistic regression models for predicting dropout.

\begin{tabular}{|c|c|c|c|c|}
\hline Models & Odds ratio & $\mathrm{Cl}$ & $z$ & $\mathrm{P}$ \\
\hline \multicolumn{5}{|c|}{ 1. \% weight loss continuous } \\
\hline$\%$ weight loss 1 month & 1.27 & $(1.09,1.48)$ & 3.10 & 0.002 \\
\hline Age & 0.98 & $(0.95,1.01)$ & -1.44 & 0.151 \\
\hline $\mathrm{BMI}$ & 1.04 & $(0.96,1.14)$ & 0.94 & 0.347 \\
\hline gender & 1.78 & $(0.89,3.57)$ & 1.63 & 0.104 \\
\hline \multicolumn{5}{|c|}{ 2. pre study variables continuous full } \\
\hline Age & 0.98 & $(0.95,0.999)$ & -2.05 & 0.041 \\
\hline BMI & 1.04 & $(0.98,1.11)$ & 1.21 & 0.225 \\
\hline Gender & 1.55 & $(0.92,2.64)$ & 1.65 & 0.098 \\
\hline \multicolumn{5}{|c|}{ 3. weight loss $\leq 2 \%$ binary } \\
\hline weight loss $\leq 2 \%$ & 5.32 & $(2.85,9.94)$ & 5.25 & $<0.001$ \\
\hline Age $\leq 50$ years & 1.96 & $(0.98,3.90)$ & 1.92 & 0.055 \\
\hline BMI & 1.05 & $(0.95,1.15)$ & 0.95 & 0.342 \\
\hline Gender & 1.74 & $(0.92,3.91)$ & 1.74 & 0.081 \\
\hline \multicolumn{5}{|c|}{ 4. weight loss $\leq 2 \%$ binary } \\
\hline weight loss $\leq 2 \%$ & 4.99 & $(2.71,9.18)$ & 5.17 & $<0.001$ \\
\hline \multicolumn{5}{|c|}{$\begin{array}{l}\text { 5. pre study variable age } \leq 50 \text { years } \\
\text { binary }\end{array}$} \\
\hline Age $\leq 50$ years & 2.07 & $(1.23,3.47)$ & 2.74 & 0.006 \\
\hline BMI & 1.04 & $(0.97,1.11)$ & 1.18 & 0.236 \\
\hline Gender & 1.50 & $(0.88,2.54)$ & 1.50 & 0.134 \\
\hline
\end{tabular}

The classification and regression tree procedure selected only percent weight loss at 1 month as the only predictor variable with a split at $1.992 \%$ weight loss (rounded to $2 \%$ for ease of application), see Figure 1. To verify these results we considered the proportion of 
participants losing weight at $0.5 \%$ increments from baseline increments starting with 0.5 to 5\%. The AUC and associated Cls are shown in Table 3. The overall wald test that the AUC were equal was significant $\mathrm{P}<0.001$ indicating at least one classifier was significantly different. As the cutoff at $2 \%$ had the highest AUC the only post hoc tests considered to reduce the risk of type 1 error were whether this cutoff was significantly different to those immediately surrounding this criteria, the $1.5 \%(P=0.0174)$ and the $2.5 \%(P=0.0004)$ cutoffs. Logistic regression for percent weight loss at 1 month as a continuous variable indicates that for every $1 \%$ reduction in the amount of weight loss the risk of dropping out increases by 1.27 times (model 1). When percent weight loss at one month and age were considered as binary variables, only weight loss $\leq 2 \%$ was significant in the entry model with those with a weight loss $\leq 2 \%$ being $5.32(2.85,9.94)$ times more likely to drop out than those with a weight loss $>2 \%$ in the first month (Model 3). Again removing age, BMI, or gender from the model did not improve the model fit $(P>0.05)$, however removing all three did improve the model $\left(X^{2}=8.37, d f=3, P=0.039\right)$, indicating that weight loss $\leq 2 \%$ was the strongest predictor of attrition (model 4). In this model participants with a weight loss $\leq 2 \%$ were $4.99(2.71,9.18)$ times more likely to drop out and those with a weight loss $>2 \%$, a finding consistent with the decision tree. 
Figure 1 Decision tree for predicting drop out with \% percent weight loss, age, BMI and gender.

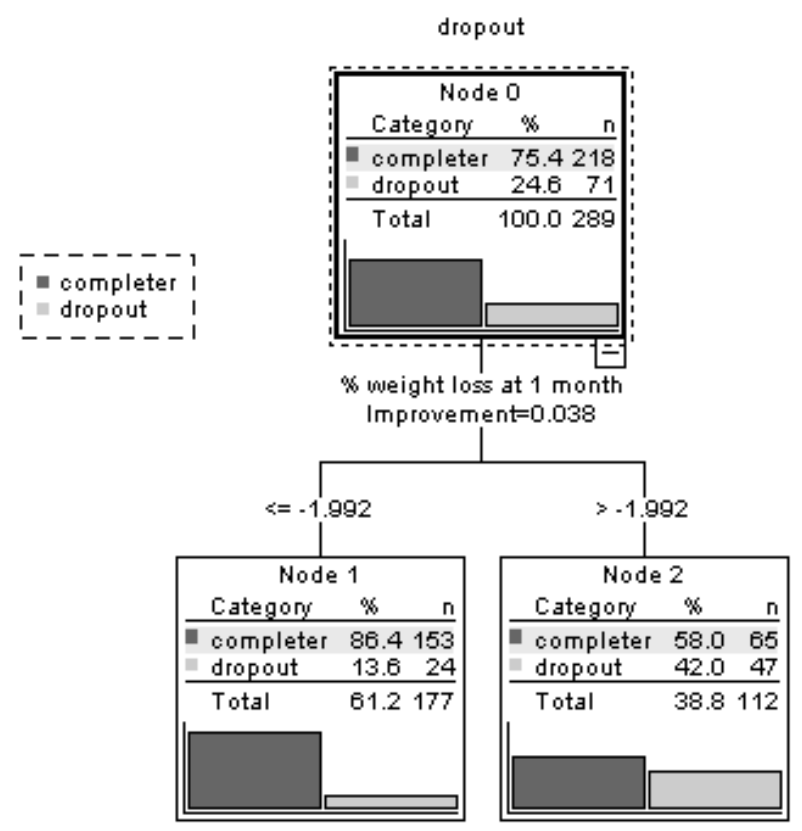


Table 3. Area under the curve, sensitivity and specificity for predicting dropout using incremental changes in percent weight loss and Age.

\begin{tabular}{|l|l|l|l|l|}
\hline & AUC & Cl & Sensitivity(\%) & Specificity(\%) \\
\hline criteria & & & & \\
\hline $0.5 \%$ & & & & \\
\hline $1.0 \%$ & 0.535 & $(0.478,0.593)$ & 18.31 & 90.37 \\
\hline $1.5 \%$ & 0.564 & $(0.496,0.633)$ & 30.99 & 84.40 \\
\hline $2.0 \%$ & 0.604 & $(0.532,0.677)$ & 45.07 & 78.90 \\
\hline $2.5 \%$ & 0.658 & $(0.589,0.727)$ & 66.20 & 69.72 \\
\hline $3.0 \%$ & 0.598 & $(0.528,0.667)$ & 67.61 & 59.63 \\
\hline $3.5 \%$ & 0.573 & $(0.513,0.633)$ & 76.06 & 49.08 \\
\hline $4.0 \%$ & 0.523 & $(0.476,0.571)$ & 81.69 & 37.16 \\
\hline $4.5 \%$ & 0.523 & $(0.476,0.571)$ & 83.10 & 25.23 \\
\hline $5.0 \%$ & 0.523 & $(0.476,0.571)$ & 85.29 & 22.16 \\
\hline 2. Age criteria & 0.523 & $(0.476,0.571)$ & 89.39 & 13.30 \\
\hline 46 & 0.574 & $(0.521,0.628)$ & 60.68 & 54.20 \\
\hline 47 & 0.578 & $(0.525,0.630)$ & 64.10 & 51.40 \\
\hline 48 & 0.593 & $(0.511,0.616)$ & 65.81 & 46.85 \\
\hline 49 & & $(0.542,0.640)$ & 75.21 & 33.01 \\
\hline 50 & $(0.549,0.636)$ & 78.63 & 39.16 \\
\hline 51 & & $(0.529,0.620)$ & 80.34 & 34.62 \\
\hline
\end{tabular}

When percent weight loss at 1 month was removed from the model to consider only those variables available pre study commencement, the decision tree model selected only age as a predictor of dropout based on a cutoff of 49.5 years (Figure 2). Using this value and the 
sample median (46) ages of 46 through to 51 were considered using the ROC curve. The AUC, sensitivity and specificity produced the best values at an age of 49 and 50 with no significant difference between the values considered $\mathrm{P}=0.135$, or by considering age 49 to age 50 as a post hoc test $\mathrm{P}=0.824$ (Table 3 ). For ease of application the value of 50 years was used in the categorical logistic regression (Model 5). Again age, BMI and gender were considered, in the entry model only age was significant however removing BMI and gender did not improve the model fit (removing $B M I X^{2}=1.40 \mathrm{df}(1) P=0.236$, removing $B M I$ and gender $\left.\mathrm{X}^{2}=3.30 \mathrm{df}(2) \mathrm{P}=0.192\right)$. Logistic regression with age as a continuous variable (model 2) indicates that for every one year increase in age the odds of dropping out decrease by $2.5 \%$. When considered as a categorical variable (model 5) those less than or equal to 50 years old were two times $(1.2,3.5)$ more likely to drop out than those older than $50, P=0.006$.

Figure 2 Decision tree for predicting drop out with age, BMI and gender.

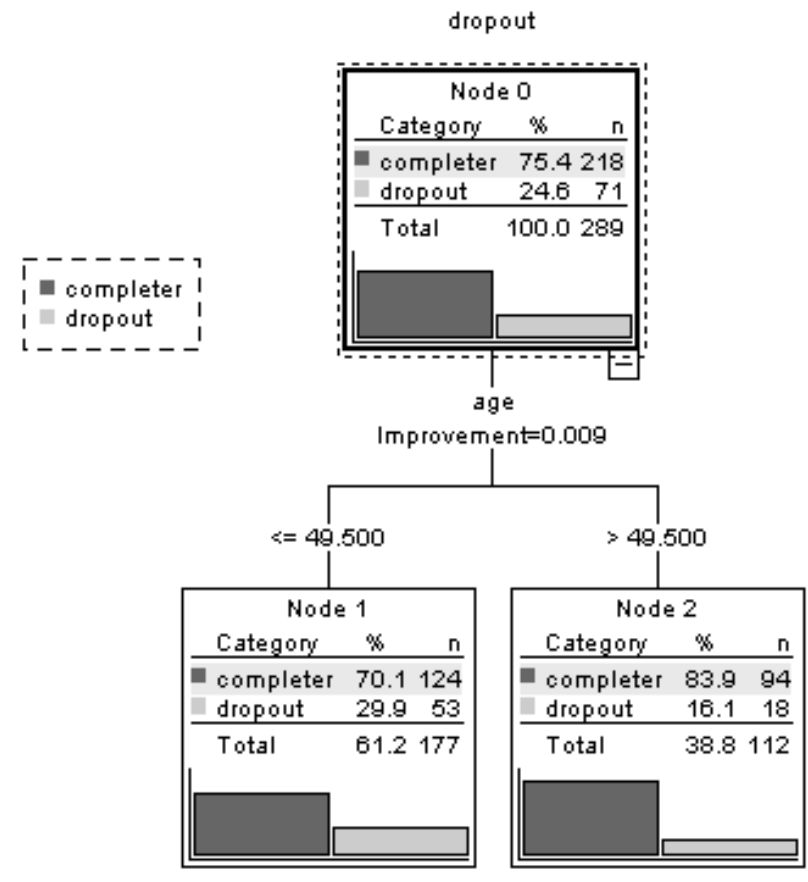




\section{Discussion}

The aim of this analysis was to demonstrate whether readily available demographic and early trial success information could be used to predict attrition in dietary weight loss trials. Two statistically significant and relevant models were considered. The first model demonstrated that greater than or equal to $2 \%$ weight loss in the first month of the study was the most significant predictor of dropout and could be used independently to predict attrition. Considering that this variable occurs after trial commencement we considered a second model using only age, BMI and gender to determine if these characteristics predict attrition. Age was the strongest predictor however there was variation between the two modelling procedures suggesting that further investigation of the role of BMI and gender in predicting dropout is warranted. Our results suggest all 3 variables should be considered in randomisation of patients to treatment arms. Given the strong impact of 1 month weight loss on predicting dropout, designs which take this initial weight loss into account are recommended.

Several researchers have previously demonstrated that initial weight loss is associated with study dropout in dietary based weight loss trials ${ }^{9-16}$, however this finding is not consistent and others have found no relationship ${ }^{11,17,18}$. This is the first study to quantify the amount of initial weight loss which predicts dropout and to investigate and quantify additional easily obtainable subject characteristics such as age which can be used to ensure adequate randomisation.

Age was considered as a variable predicting attrition in 33 studies in the review conducted by Moroshko and colleagues with 17 studies finding no relationship, 13 showing an association with younger age, 1 study showing an association with younger age in women 
and not men and only 2 small studies finding dropout associated with older age ${ }^{2}$. Since the publication of this review a further study has supported the relationship between attrition and younger age $\mathrm{e}^{15}$, with a further four studies showing no relationship ${ }^{9,17-19}$. A recent pooled analysis of individual patient data from 10 large obesity RCTs in the US showed a significantly increased risk of dropout with advancing age (HR 1.02, 95\% Cl 1.01,1.02) ${ }^{20}$ however weight loss was not the primary outcome in most of these studies therefore it is possible that the subjects in these studies differ from those in studies focussed primarily on weight loss, the dropout rates were low (3.7-17.2\%) compared with the averages reported in previous research $(23 \%, 26.3 \%)^{21,22}$ and the range in the systematic review $(7-90 \%)^{2}$. It is also important to consider that these papers generally represent secondary, unplanned, post hoc analyses and particularly with respect to the papers showing no effect there is a high risk of type 2 error, that is the studies have insufficient power to demonstrate a significant effect. In view of this limitation and the different study outcomes in the recent pooled analysis it is reasonable to suggest that younger age predicts attrition in weight loss studies. The current research quantifies this difference suggesting that those participants younger than 50 years are at greater risk of attrition than those 50 and older.

The consideration that analyses investigating attrition are generally post hoc and unplanned also makes the relationship between attrition and gender and attrition and initial weight or BMI unclear as the majority of studies show no relationship ${ }^{2,15,19}$. Where a relationship does exist it appears that females may be more likely to drop out than males ${ }^{2}$, although a more recent study has shown that males are more likely to drop out than females ${ }^{23}$. The 2011 systematic review found roughly equal (but small $n=4-5$ ) numbers of papers supporting a relationship between high or low initial weight and attrition compared with 18 reporting no relationship more recent papers continue to differ with some supporting the relationship between higher initial weight ${ }^{18,20}$ and attrition and some lower initial weight ${ }^{15}$ (although no relationship is still the most frequent ${ }^{9,17,19}$ ). 
Behavioural and psychological characteristics have been shown to be associated with trial dropout in previous research, although reporting is inconsistent and methodology differs ${ }^{2}$. We support the view of others ${ }^{2,15}$ that these factors should be the focus of the interventions administered in the weight loss trials and should be measured to determine ways of improving the retention rates in dietary and lifestyle related weight loss trials. The focus of this paper however is on factors associated with the initial trial design. Measuring initial weight change is an easy and consistent way to identify potential attrition in weight loss trials. One month was the earliest time point at which weight was recorded in the weight loss trials studied here. Recent research has demonstrated that weight loss as early as one week $^{16}$ or BMI changes as early as two weeks may be predictive of dropout ${ }^{10}$ and future research should investigate the role of weekly monitoring to quantify the risk of dropout.

This research highlights two particular variables, initial weight loss and age, which were predictive of attrition in our study samples. The trials considered here recruited subjects with similar demographic characteristics and the particular cutoffs relevant for our studies may not be relevant for other study populations. For example the NUGENOB study ${ }^{16}$ only recruited subjects between 20-50 years of age and therefore different age stratification was warranted. The intention of this analysis is to raise awareness of the need to consider different study populations and design interventions incorporating known potential covariates that may predict attrition in the relevant demographic group. The variables considered in this analysis, particularly initial weight loss are also associated with predicting the amount of weight lost (success) in obesity management trials and although this was beyond the scope of the current analysis, several papers have reported this ${ }^{16,23-25}$. 
Further implications of this analysis are that weight loss trial designs should be investigated where an initial treatment period common to all participants is introduced followed by stratification based on weight loss in the initial weeks or months of the study. As the amount of the weight loss in the first month was independent of treatment assignment in this analysis it is possible that this initial response is related more to participant characteristics than treatment effects. New design methods such as sequential multiple assignment should be considered where the initial response is part of the study design ${ }^{26}$. Here all participants are randomised at least once, however those who fail to respond at a predefined time point are further randomised into more than one treatment option. Adaptive designs where randomisation of incoming subjects in based on the early weight loss of existing subjects could also be considered ${ }^{27}$. The potential for the use of these designs in weight loss, sample size estimation and analysis is covered in detail in Almirall et $\mathrm{al}^{26}$. In these designs specific strategies could be implemented for those not responding in the initial phase and this difference in initial response can then be modelled appropriately in the analysis.

There were some limitations to this study. Other variables which are routinely collected at study entry could also be considered in models predicting dropout. Education level and occupation have also been shown to be associated with attrition, this information was not collected for all subjects in the study and the inclusion of these variables reduced the size of the dataset. Given that some studies have shown relationships with BMI and gender and attrition $^{2}$, it may be the case that our sample size was inadequate to demonstrate these relationships, particularly given the range of significance for gender was $\mathrm{P}=0.081-0.134$ in the models. Further research should be done on larger studies and pooled datasets to definitively investigate these relationships and to determine if higher sensitivity and specificity can be obtained. Data on the one month weight loss was also not available for all subjects and it would certainly be a recommendation of this research that early weight 
change information should be routinely collected in all weight loss studies given the strong association shown in this and other studies with both attrition and weight loss success.

In conclusion demographic variables such as age should be routinely used to stratify patients on study entry, while the role of gender and BMI were less apparent in this study it would be prudent to consider these in the randomisation as well. Early weight changes in the initial part of weight loss interventions should be incorporated in the design process.

1. MacLean PS, Wing RR, Davidson T, Epstein L, Goodpaster B, Hall KD et al. NIH working group report: Innovative research to improve maintenance of weight loss. Obesity (Silver Spring, Md.) 2015; 23(1): 7-15. e-pub ahead of print 2014/12/04; doi: 10.1002/oby.20967

2. Moroshko I, Brennan L, O'Brien P. Predictors of dropout in weight loss interventions: a systematic review of the literature. Obesity Reviews 2011; 12(11): 912-934. doi: 10.1111/j.1467-789X.2011.00915.x

3. Tapsell LC, Batterham MJ, Thorne RL, O'Shea JE, Grafenauer SJ, Probst YC. Weight loss effects from vegetable intake: a 12-month randomised controlled trial. Eur J Clin Nutr 2014; 68(7): 778-785. e-pub ahead of print 2014/03/29; doi: 10.1038/ejcn.2014.39

4. Tapsell LC, Batterham MJ, Charlton KE, Neale EP, Probst YC, O'Shea JE et al. Foods, nutrients or whole diets: effects of targeting fish and LCn3PUFA consumption in a 12 mo weight loss trial. BMC public health 2013; 13: 1231. e-pub ahead of print 2013/12/29; doi: 10.1186/1471-2458-13-1231

5. Tan SY, Tapsell L, Batterham M, Charlton K. Defining the functional properties of dietary protein and protein-rich foods in human energy expenditure. Nutrition \& Dietetics 2008; 65: S66-S70. doi: 10.1111/j.1747-0080.2008.00264.x

6. Tapsell L, Batterham M, Huang XF, Tan SY, Teuss G, Charlton K et al. Short term effects of energy restriction and dietary fat sub-type on weight loss and disease risk factors. Nutrition, Metabolism and Cardiovascular Diseases 2010; 20(5): 317-325.

7. Hastie T, Tibshirani R, Friedman J. The elements of statistical learning: Data mining, inference, and prediction, 2nd edn Springer: NY, NY, 2009. 
8. Breiman L, Friedman JH, Olshen RA, Stone CJ. Classification and regression trees, Wadsworth \& Brooks/Cole Advanced Books \& Software: Monterey, CA, 1984.

9. Messier V, Hayek J, Karelis AD, Messier L, Doucet E, Prud'homme D et al. Anthropometric, metabolic, psychosocial and dietary factors associated with dropout in overweight and obese postmenopausal women engaged in a 6-month weight loss programme: a MONET study. The British journal of nutrition 2010; 103(8): 1230-1235. e-pub ahead of print 2009/11/26; doi: 10.1017/s0007114509993023

10. Yackobovitch-Gavan M, Steinberg DM, Endevelt R, Benyamini Y. Factors associated with dropout in a group weight-loss programme: a longitudinal investigation. Journal of Human Nutrition and Dietetics 2015; 28(Suppl 2): 33-40. doi: 10.1111/jhn.12220

11. Bernier M, Avard J. Self-efficacy, outcome, and attrition in a weight-reduction program. Cognitive therapy and research 1986; 10(3): 319-338. doi: 10.1007/BF01173469

12. Brownell KD, Heckerman $\mathrm{CL}$, Westlake RJ. The behavioral control of obesity: a descriptive analysis of a large-scale program. Journal of clinical psychology 1979; 35(4): 864-869. e-pub ahead of print 1979/10/01;

13. Mitchell C, Stuart RB. Effect of self-efficacy on dropout from obesity treatment. Journal of consulting and clinical psychology 1984; 52(6): 1100-1101. e-pub ahead of print 1984/12/01;

14. Packianathan I, Sheikh M, Boniface D, Finer N. Predictors of programme adherence and weight loss in women in an obesity programme using meal replacements. Diabetes, obesity \& metabolism 2005; 7(4): 439-447. e-pub ahead of print 2005/06/16; doi: 10.1111/j.14631326.2004.00451.x

15. Colombo O, Ferretti VV, Ferraris C, Trentani C, Vinai P, Villani S et al. Is drop-out from obesity treatment a predictable and preventable event? Nutr J 2014; 13: 13. e-pub ahead of print 2014/02/05; doi: 10.1186/1475-2891-13-13

16. Handjieva-Darlenska T, Holst C, Grau K, Blaak EE, Martinez JA, Oppert JM et al. Clinical correlates of weight loss and attrition during a 10-week dietary intervention study: results from the NUGENOB project. Obes Facts 2012; 5: 928-936.

17. Elfhag $\mathrm{K}$, Rossner S. Initial weight loss is the best predictor for success in obesity treatment and sociodemographic liabilities increase risk for drop-out. Patient Educ Couns 2010; 79(3): 361-366. e-pub ahead of print 2010/03/13; doi: 10.1016/j.pec.2010.02.006

18. Ortner Hadziabdic M, Mucalo I, Hrabac P, Matic T, Rahelic D, Bozikov V. Factors predictive of drop-out and weight loss success in weight management of obese patients. Journal of human nutrition and dietetics : the official journal of the British Dietetic Association 2014. epub ahead of print 2014/09/16; doi: 10.1111/jhn.12270 
19. Michelini I, Falchi AG, Muggia C, Grecchi I, Montagna E, De Silvestri A et al. Early dropout predictive factors in obesity treatment. Nutrition research and practice 2014; 8(1): 94-102. epub ahead of print 2014/03/13; doi: 10.4162/nrp.2014.8.1.94

20. Kaiser KA, Affuso O, desmond RA, Allison DB. Baseline participant characteristics and risk for dropout from ten obesity randomized controlled trials: a pooled analysis of individual level data. Frontiers in Nutrition 2015. e-pub ahead of print 24 Nov 2014;

21. Elobeid MA, Padilla MA, McVie T, Thomas O, Brock DW, Musser B et al. Missing data in Randomised Clinical Trials for weight loss: Scope of the problem, state of the field, and performance of statistical methods. PLOS ONE 2009; 4(8): e6624. e-pub ahead of print August 13, 2009;

22. Batterham MJ, Tapsell LC, Charlton KE. Analyzing weight loss intervention studies with missing data: Which methods should be used? Nutrition 2013; 29(7-8): 1024-1029.

23. Handjieva-Darlenska T, Handjiev S, Larsen TM, Van Baak M, Lindroos AK, Papadaki A et al. Predictors of weight loss maintenance and attrition during a 6-month dietary intervention period: results from the DIOGenes study. Clinical Obesity 2011; 1: 62-68.

24. Handjieva-Darlenska T, Handjiev S, Larsen TM, Van Baak M, Jebb S, Papadaki A et al. Initial weight loss on an 800-kcal diet as a predictor of weight loss success after 8 weeks: the Diogenes study. Eur J Clin Nutr 2010; 64: 994-999.

25. Thomas DM, Ivanescu AE, Martin CK, Heymsfield SB, Marshall K, Bodrato VE et al. Predicting successful long-term weight loss from short-term weight-loss outcomes: new insights from a dynamic energy balance model (The POUNDS Lost study). The American Journal of Clinical Nutrition 2015. e-pub ahead of print December 24, 2014; doi: 10.3945/ajcn.114.091520

26. Almirall D, Nahum-Shani I, Sherwood NE, Murphy SA. Introduction to SMART designs for the development of adaptive interventions: with application to weight loss research. Translational behavioral medicine 2014; 4(3): 260-274. e-pub ahead of print 2014/09/30; doi: 10.1007/s13142-014-0265-0

27. Chow SC, Chang M. Adaptive design methods in clinical trials - a review. Orphanet journal of rare diseases 2008; 3: 11. e-pub ahead of print 2008/05/06; doi: 10.1186/1750-1172-3-11 